\title{
THE INFLUENCE OF WAVE EXPOSURE ON CORAL COMMUNITY DEVELOPMENT ON MAN-MADE BREAKWATER REEFS, WITH A COMPARISON TO A NATURAL REEF
}

\author{
John Burt, David Feary, Paolo Usseglio, \\ Andrew Bauman, and Peter F. Sale
}

\begin{abstract}
Breakwaters dominate shorelines in many coastal urban areas, providing substantial hard-bottom habitat upon which diverse and abundant reef communities develop. In recognition of their potential ecological and economic importance, there is increasing interest in understanding how design features can influence community development. We investigated the influence of wave exposure on breakwater coral communities in Dubai, United Arab Emirates. Coral community composition, cover, size structure, recruitment, mortality, and growth rates were compared quarterly between two windward and two leeward breakwater sites for $1 \mathrm{yr}$ to explore the influence of wave exposure on coral community development. Comparisons also were made with a natural coral reef to gain an understanding of how community structure and dynamics compare between these habitats. Benthic and water column sediment particle sizes were also analyzed. Leeward breakwaters contained a low-cover coral community dominated by small colonies with high mortality compared with windward breakwaters and the natural reef. Windward breakwater coral communities had comparable recruitment, mortality, and growth rates as the natural reef. Fine sediments $(<63 \mu \mathrm{m})$ dominated the benthos and water column on leeward breakwaters, while windward breakwaters and the natural reef were dominated by sediments with larger size classes $(>125 \mu \mathrm{m})$, likely as a result of differences in wave action among reef types. Overall, these results suggest that leeward breakwaters represent sub-optimal habitats for coral community development. However, with appropriate design, breakwaters can develop diverse and abundant coral communities with comparable coral cover, demographics, and growth rates to those on the natural reef in Dubai.
\end{abstract}

Coastal defense structures such as breakwaters, groynes, and sea-walls are becoming increasingly common features in coastal urban areas. Such structures now make up more than half of the coastline in many regions (Bacchiocchi and Airoldi, 2003; Airoldi et al., 2005; Hansen, 2005; Wen et al., 2007) and provide a substantial amount of hard-bottom habitat upon which diverse and abundant fish and benthic communities can develop (Lincoln-Smith et al., 1994; Pondella et al., 2002; Bulleri, 2005b; Guidetti et al., 2005; Moschella et al., 2005; Burt et al., 2009b). In tropical and subtropical areas, such structures can develop extensive coral communities that provide food, settlement habitat, and shelter for a variety of reef organisms (Wen et al., 2007; Burt et al., 2009a,b), while increasing their aesthetic appeal and recreational value (Airoldi et al., 2005). Such artificial structures can also be of value in replacing or enhancing natural coral reefs that have been degraded by natural or anthropogenic stress (Clark and Edwards, 1999; Miller, 2002) and may increase productivity in areas where natural reef habitat is limiting (Carr and Hixon, 1997). However, coastal defense structures can also have negative implications for marine management by supporting communities that can be less diverse and structurally different from natural 
reef communities (Moschella et al., 2005; Clynick et al., 2008; Burt et al., 2009b), by having assemblages that can have different recruitment, predation, and other functional attributes compared with those in natural habitats (Bulleri, 2005a,b; Burt et al., 2009b), and by serving as stepping stones for the spread of some invasive species (Bulleri and Airoldi, 2005; Bulleri et al., 2006; Vaselli et al., 2008).

In recognition of their potentially important ecological role, it is important to understand how design features of coastal defense structures can influence the development of associated communities (Baine, 2001; Airoldi et al., 2005). One of the fundamental aspects of structural design that may influence community development is their exposure to wave action. Differing levels of wave exposure can substantially influence the composition and abundance of benthic communities on coastal defense structures in temperate environments (Southward and Orton, 1954; Moschella et al., 2005), and have been associated with differences in coral community structure on natural coral reefs in the tropics (Riegl and Piller, 1997; Reinicke et al., 2003; Steiner, 2003). However, the influence of wave exposure on the development of coral communities on coastal defense structures is unknown. Differences in wave exposure regimes may affect the relative abundance of fine sediments in the water column and benthic sediments. Fine sediments can inhibit coral recruitment, growth, and survival (Hodgson, 1990; Birrell et al., 2005; Crabbe and Smith, 2005), and have been associated with differences in the structure of the wider benthic community on natural reefs and breakwaters (Purcell, 2000; Walker, 2007; Burt et al., 2009b). Understanding how wave exposure influences coral community dynamics via differences in sediment characteristics could allow more appropriate design of coastal defense structures.

The purpose of this study was to investigate the influence of wave exposure on the development of coral communities associated with breakwaters in Dubai, United Arab Emirates. Breakwaters are a dominant feature in the marine environment of Dubai, where $>65 \mathrm{~km}$ of rocky breakwater have been added to the $50 \mathrm{~km}$ of natural sandy coastline in the past decade (Hansen, 2005; Burt et al., 2009a). The addition of this artificial hard-bottom habitat may be particularly important here, where corals are generally restricted to a narrow $10 \mathrm{~km}$ long near-shore band of small, discontinuous patch reefs in western Dubai, and the remaining coastal area is dominated by mobile sands and silt unsuitable for coral reef development (Riegl, 1999; Burt et al., 2008). We compared coral community composition, cover, size structure, recruitment, mortality, and growth rates as well as benthic and water column sediment particle-size distributions between leeward and windward breakwaters to explore the influence of wave exposure on coral community development. These were compared to measurements on a natural coral reef to gain an understanding of how coral community structure and dynamics compare between these artificial and natural habitats in Dubai.

\section{Methods}

Field SAmpling.-Between July 2007 and 2008, we examined coral reef communities throughout the coastline of Dubai, United Arab Emirates. The seabed in this area is dominated by mobile sand and silt substrates (Burt et al., 2008), with natural coral habitat restricted to isolated areas of exposed cap-rock which occur mainly to the south-west of Dubai (Fig. 1; and see Burt et al., 2008). Large-scale (> $2 \mathrm{~km}$ long) breakwaters also provide a substantial 


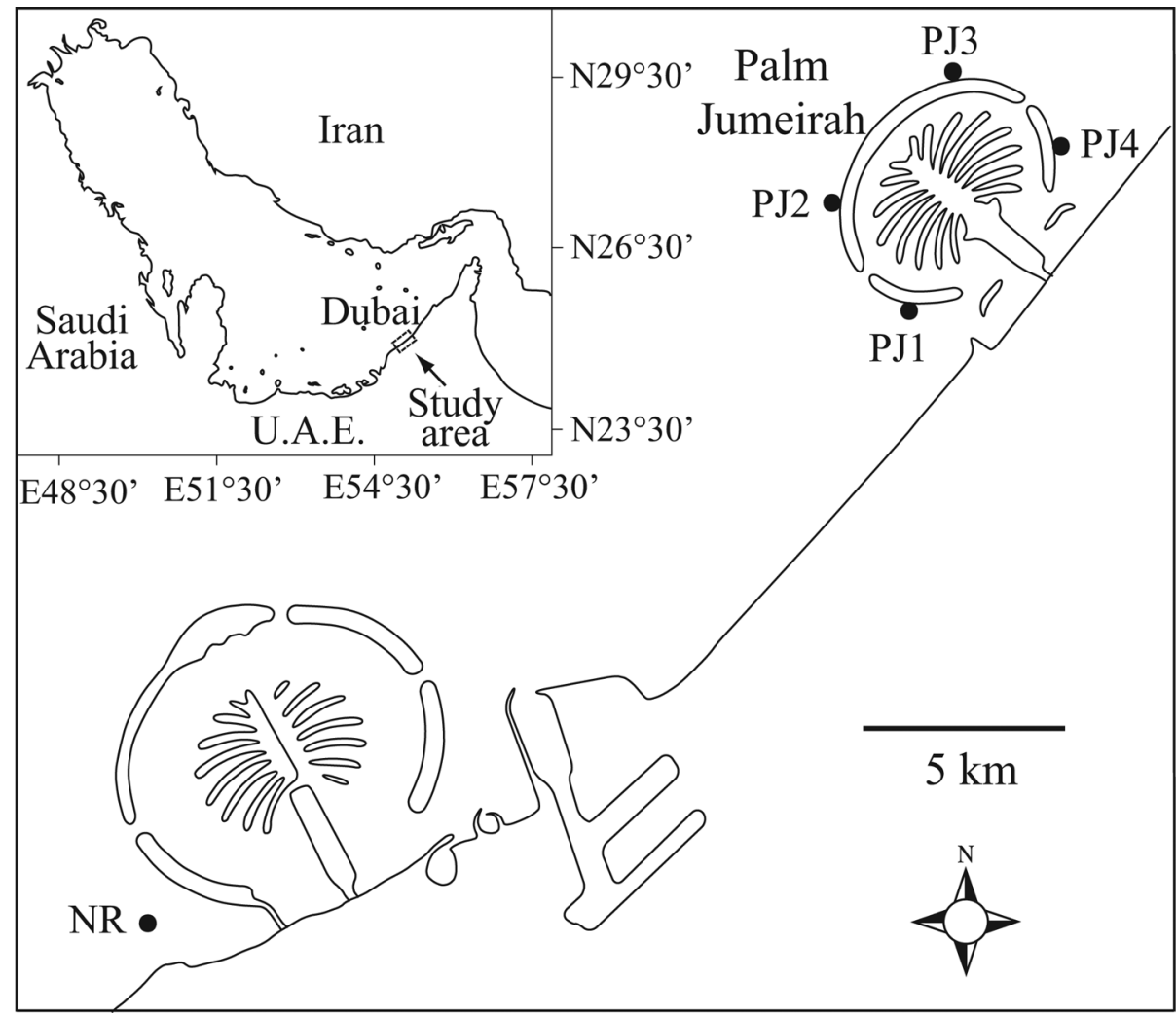

Figure 1. Map of study sites on leeward (PJ1 and PJ4) and windward (PJ2 and PJ3) breakwaters and on the natural reef (NR).

amount of hard-bottom habitat upon which coral and benthic communities develop (Burt et al., 2009a,b). One such breakwater, on the Palm Jumeirah development, was constructed in 2002 from approximately $225,000 \mathrm{~m}^{2}$ of quarried rock, with an estimated volume exceeding 1.2 million $\mathrm{m}^{3}$ (Fig. 1). Sampling was conducted at two leeward (PJ1 and PJ4) and two windward (PJ2 and PJ3) sites on the Palm Jumeirah breakwater, as well as at a natural reef site within the only natural reef in Dubai (NR; Fig. 1). The depth to sea bottom at all locations was $<9 \mathrm{~m}$. The natural reefs in Dubai have been substantially impacted by past coastal development in recent years, with the construction of the Palm Jebel Ali and the Dubai Waterfront islands resulting in the direct loss of most of the coral habitat from the area (Burt et al., 2008, $2009 \mathrm{~b})$. Although it would be preferable from a design perspective to sample multiple natural reef locations, the site sampled here represents the last remaining large coral reef patch in Dubai. This site has similar environmental conditions and coral community structure to reefs previously described in the area (Riegl, 1999; Burt et al., 2008). Thus, although the single site makes for limited generalizations, it is representative of natural conditions in Dubai.

Ten permanent $0.25 \mathrm{~m}^{2}$ quadrats were established at approximately 5-6 m depth at each site. Stainless steel bolts were installed to mark the corners of each permanent quadrat using a Chicago Pneumatic CP-9 hammer-drill, and quadrats were spaced 3-5 m apart. Because there is limited vertical relief on the natural reef (Riegl, 1999; Burt et al., 2008), quadrats on the breakwater were installed only on approximately horizontal substrates for consistency. Quadrats were photographed quarterly from July 2007 through July 2008 to obtain temporal estimates of changes in coral cover, demographics (recruitment and mortality), and growth rates. Sampling periods were defined as summer (July-October 2007), fall (October 2007- 
January 2008), winter (January-April 2008), and spring (April-July 2008). All photographs were captured with a Nikon D-80 10-megapixel digital camera mounted on a PVC frame outlining the quadrat area.

CPCe image analysis software (Kohler and Gill, 2006) was used to calculate the area of individual colonies quarterly, and this information was used to calculate temporal changes in total coral cover and growth rates. Growth rates calculations were based on colony diameter rather than planar area to avoid possible confounding effects of differences in areal growth rates among colonies of different size; diameter $(D)$ was calculated as $D=2 \sqrt{ }(A / \pi)$, where $A$ = area, assuming circular colonies. Demographic changes in recruitment and mortality were also assessed quarterly, with recruitment defined as the appearance of a new colony within a quadrat, while mortality was defined as the permanent loss of a colony from a quadrat. Sizefrequency distributions were created using the mean number of colonies in each size-class across sampling periods. Juveniles were defined as those with an area $<12.5 \mathrm{~cm}^{2}$, equating with a circular colony $<4 \mathrm{~cm}$ in diameter (after Bak and Engel, 1979; Rogers et al., 1984; Chiappone and Sullivan, 1996; Edmunds, 2007). Mobile coral rubble was excluded from all analyses, and colonies which were partially or fully obscured by the quadrat frame during any season were not included in demographics or growth rate analyses to avoid confounding these estimates.

ANALYSES.-Reefs were classified as leeward breakwater, windward breakwater, or natural reef for analyses. Data were pooled from both sites on each breakwater exposure, as preliminary analyses indicated no differences in coral cover, recruitment, mortality, or linear growth rates between sites for both the leeward (repeated measures ANOVAs: $F=0.01,0.03,2.0,0.8$, $\mathrm{P}>0.05$ each, respectively) and windward reefs (repeated measures ANOVAs: $F=0.9,2.2,1.3$, $0.9, \mathrm{P}>0.05$ each, respectively), and to provide a balanced design for analyses. Percent coral cover was converted to proportions and arc-sine square-root transformed, while a cube-root transformation was applied to growth data to account for the occurrence of negative coral growth rates. Estimates of recruitment and mortality were $\log _{(\mathrm{n}+1)}$ transformed. Repeated measures ANOVAs were then used to test differences in coral cover and coral growth rates between reef types and sampling periods. To account for differences in sample sizes among reef types, post-hoc unequal-N HSD tests were used to identify significantly different groups. In addition, transformed data were linearly regressed to examine the relationship between colony size and growth rates, averaged across seasons. As $\log _{(\mathrm{n}+1)}$ transformations failed to normalize demographic data, and samples were limited to 10 replicate quadrats at each site, differences in coral recruitment and mortality among sampling periods were tested with nonparametric pair-wise Friedman's ANOVAs, while differences among reef types in both demographic factors were tested using Kruskal-Wallis ANOVA by ranks.

To assess the effect of wave exposure on localized sedimentation, sediment particle size distribution was examined among reef types using sediments collected from the benthos and from water column sediment collectors mounted $0.5 \mathrm{~m}$ above the benthos. Benthic sediments were collected at each of the four breakwater sites and the natural reef using a handheld sediment collector ( $15 \mathrm{~cm}$ long, $5.2 \mathrm{~cm}$ diameter), approximately $5 \mathrm{~m}$ from the base of the breakwater or coral reef. Water column sediment collectors were constructed from $40 \mathrm{~cm}$ long, 5.2 $\mathrm{cm}$ diameter PVC pipes installed vertically at each site. All sediment samples were burned at $600{ }^{\circ} \mathrm{C}$ for $24 \mathrm{hrs}$ to remove organic matter, weighed, and sieved through $2 \mathrm{~mm}, 1 \mathrm{~mm}, 500$ $\mu \mathrm{m}, 250 \mu \mathrm{m}, 125 \mu \mathrm{m}$, and $63 \mu \mathrm{m}$ mesh. The dry mass of each fraction was used to calculate the proportional abundance of each size-class, and data were pooled across sites for each reef type. Particle size distributions were compared graphically. 


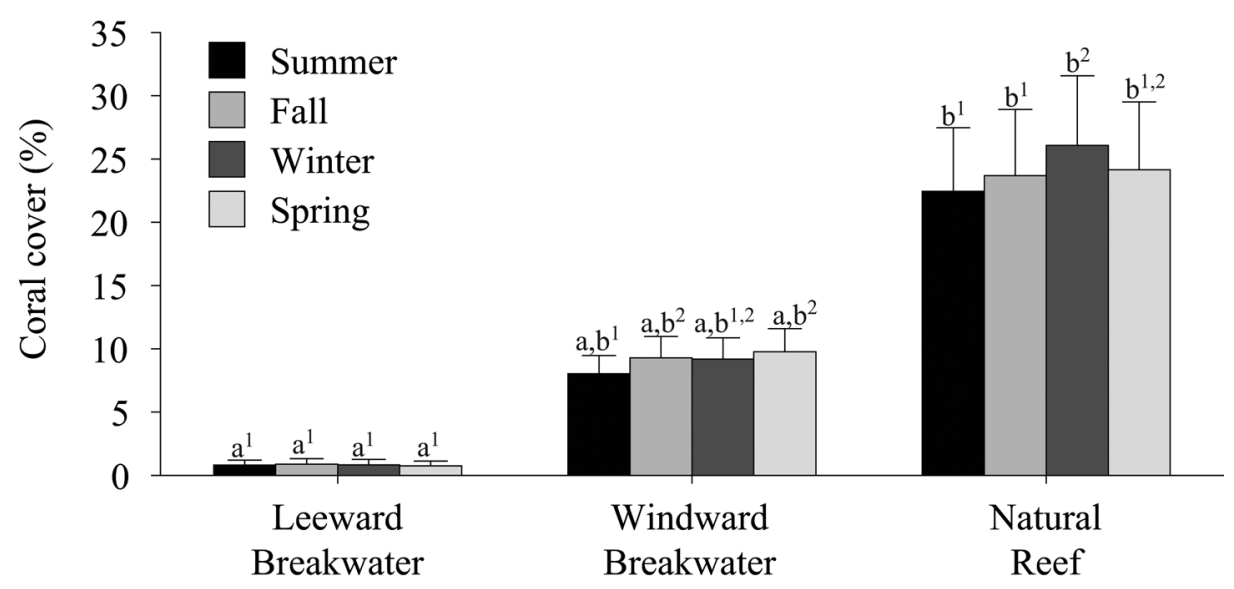

Figure 2. Seasonal coral cover (mean \pm SE \%) on leeward and windward breakwaters and the natural reef. Different letters above bars indicate significant differences between reef types; different superscript numerals indicate significant differences between sampling periods within each site (Unequal-N HSD test, $\mathrm{P}<0.05$ ).

\section{RESUlTS}

Coral Cover and Species Richness.-There was comparable coral species richness between the breakwaters and natural reef with 10 and 12 species observed on each, respectively. However, species dominance differed between reef types, with coral cover on the breakwater dominated by Favia pallida (Dana, 1846) (52.1\% of coral cover), Porites lobata (Dana, 1846) (19.5\%), and Porites lutea (Milne-Edwards and Haime, 1860) (13.1\%), while the natural reef was dominated by P. lutea (35.8\% of cover), Porites harrisoni (Veron, 2002) (31.3\%), and Cyphastrea microphthalma (Lamarck, 1816) (23.4\%). The relative proportion of P. lobata and P. lutea did not differ with exposure on the breakwater reef (repeated measures ANOVA: $F_{(1,37)}=0.7$ and 3.8, respectively, P > 0.05 each). However, F. pallida was significantly more common on the windward breakwater sites than at leeward locations (repeated measures ANOVA: $\left.F_{(1,37)}=19.3, \mathrm{P}<0.001\right)$. Species-specific coral cover, recruitment, mortality, and growth rates for each season at each location are provided in Appendix 1.

Repeated measure ANOVA of coral cover indicated a significant interaction between reef type and sampling period $\left(F_{(6,138)}=7.7, \mathrm{P}<0.001\right)$. Post hoc Tukey's unequal-N HSD tests indicated that the leeward breakwater had significantly lower coral cover than the natural reef during each sampling period ( $\mathrm{P}<0.05$ each), but that coral cover on the windward breakwater did not differ from either the leeward breakwater or the natural reef at any time $(\mathrm{P}>0.05$; Fig. 2$)$. In addition, coral cover did not change through the year on the leeward breakwater, while temporal changes in coral cover were observed on the windward breakwater and the natural reef (Fig. 2). There was a significant increase in the amount of coral cover on the windward breakwater at the end of the year compared with the previous summer (Unequal N-HSD: P < 0.001; Fig. 2). In comparison, on the natural reef, coral cover increased significantly from summer to winter $(\mathrm{P}<0.001)$, and then declined in the spring such that it did not differ from any previous sampling period (Fig. 2). Several large breakwaters were constructed within a kilometer of this natural reef site during the 

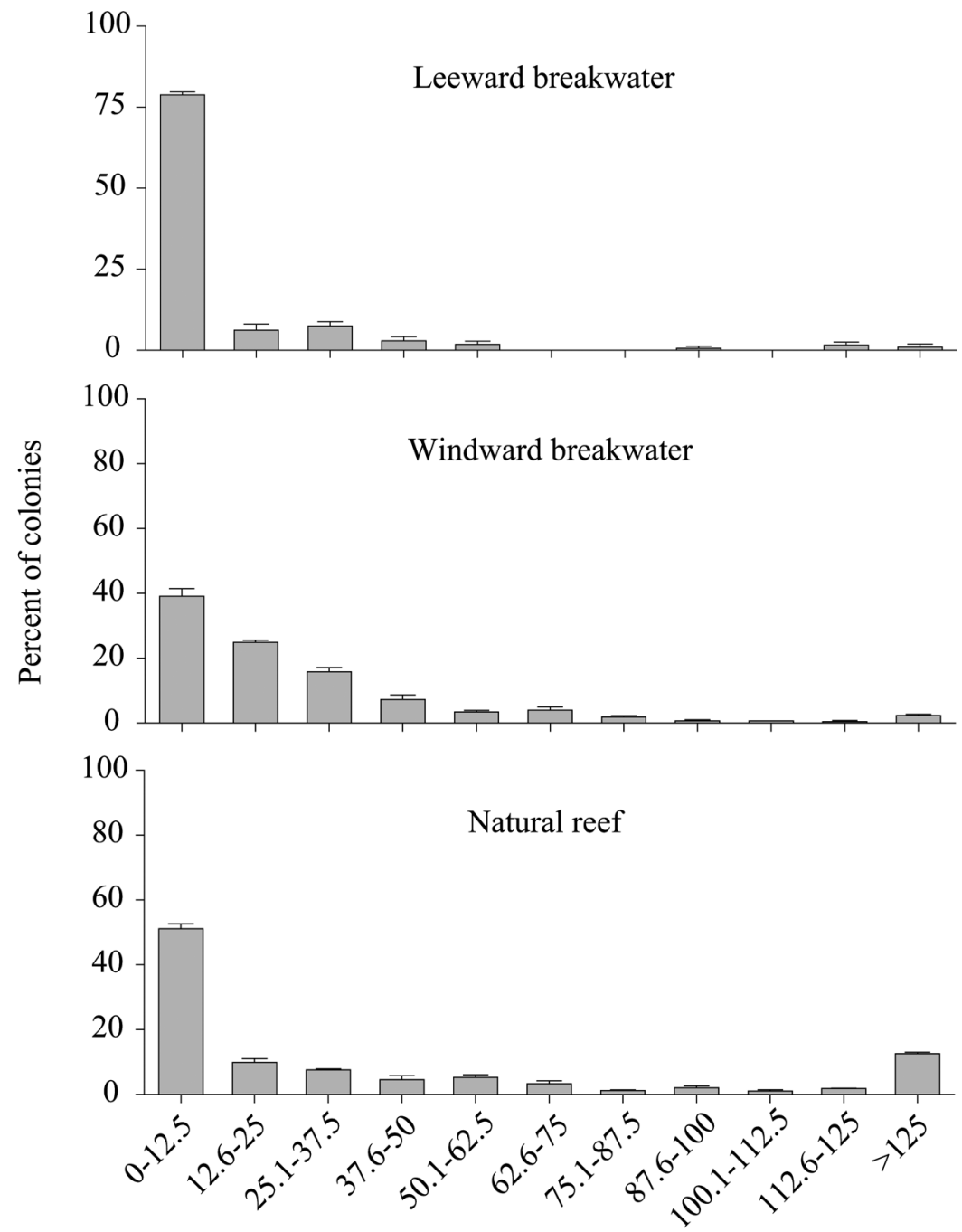

Colony size $\left(\mathrm{cm}^{2}\right)$

Figure 3. Frequency distribution of mean $( \pm$ SE) coral colony sizes among leeward and windward breakwaters and the natural reef.

spring, and the decline in live coral cover during this period likely reflects impacts from associated sedimentation on corals in the natural reef.

Size-Class Structure.-Juvenile colonies $\left(<12.5 \mathrm{~cm}^{2}\right.$ area; $<4 \mathrm{~cm}$ diameter) were the most common size class observed at all reef types. However, the relative abundance of juveniles differed between reef types. Juveniles made up over threequarters of all colonies observed on the leeward breakwater, and few colonies were observed in larger size classes (Fig. 3), which may indicate that few colonies survive to reach adulthood at this reef type. On the windward breakwater, there was a higher proportion of colonies in medium size classes $\left(<75 \mathrm{~cm}^{2}\right)$, resulting in a lower relative abundance of juveniles on this reef type (Fig. 3). The relatively infrequent occurrence 
Table 1. Seasonal coral recruitment and mortality (mean \pm SE colonies $\mathrm{m}^{-2} \mathrm{yr}^{-1}$ ) at two leeward breakwater, two windward breakwater, and one natural reef site in Dubai, U.A.E., from July 2007 to July 2008.

\begin{tabular}{lccccccccc}
\hline & \multicolumn{4}{c}{ Recruitment } & & \multicolumn{4}{c}{ Mortality } \\
\cline { 2 - 5 } \cline { 7 - 9 } Site & Summer & Fall & Winter & Spring & & Summer & Fall & Winter & Spring \\
\hline $\begin{array}{l}\text { Leeward } \\
\text { breakwater }\end{array}$ & - & $6.4 \pm 2.1$ & - & - & & - & $2.1 \pm 1.5$ & $3.2 \pm 1.7$ & $6.4 \pm 2.1$ \\
$\begin{array}{l}\text { Windward } \\
\text { breakwater }\end{array}$ & - & $3.6 \pm 2.8$ & - & - & & - & $0.9 \pm 0.9$ & $3.6 \pm 2.1$ & $3.6 \pm 1.6$ \\
Natural reef & - & $12.8 \pm 9.9$ & $3.2 \pm 3.1$ & $1.6 \pm 1.5$ & $3.2 \pm 2$ & $3.2 \pm 3.4$ & $3.2 \pm 4.7$ & $16 \pm 10$ \\
\hline
\end{tabular}

of large $\left(>75 \mathrm{~cm}^{2}\right)$ colonies on either the leeward or windward breakwaters is not surprising, given the relatively young age of these breakwaters (constructed in 2002). There was a more equitable distribution of corals in medium to large colony sizeclasses on the natural reef, with $1 / 8$ of all colonies falling into the largest size class $(>$ $125 \mathrm{~cm}^{2}$ ).

Recruitment and Mortality.-Overall, densities of new recruits averaged 0.5 $\pm 0.2 \mathrm{~m}^{-2}$ across all sites throughout the study, with new recruits accounting for $9.5 \%$ of all corals observed. However, there was a loss of an average of $0.8 \pm 0.3$ colonies $\mathrm{m}^{-2}$ of all sizes during each sampling period across sites, representing $16.2 \%$ of all colonies over the year.

Coral recruits were observed exclusively in the fall on breakwaters, and the highest densities of recruits within the natural reef were also found during this period (Table 1). Pair-wise Friedman's ANOVA indicated that recruitment was higher during the fall than any other sampling period (Fall-Summer $X=13.0$, Fall-Winter $X=$ 9.3, Fall-Spring $X=10.3$; $P<0.01$ each), with no difference in recruitment between all other sampling periods. Further, Kruskal-Wallis ANOVA by ranks indicated no significant difference in recruitment among reef types during any sampling period $\left(H_{(2,42)}\right.$ Summer $=0.0$, Fall $=5.1$, Winter $=3.3$, Spring $=3.3, \mathrm{P}>0.05$ each $)$. In addition to recruitment, coral mortality differed significantly among sampling periods (Table 1; Friedman's ANOVA: $\mathrm{X}=15.6, \mathrm{P}<0.01$ ). The highest mortality occurred during spring, when mortality was significantly higher than in summer and fall (Friedman's ANOVA: $X=14.0$ and $X=6.3$, respectively, $\mathrm{P}<0.05$ each). Mortality was also higher in winter than in summer $(\mathrm{X}=4.5, \mathrm{P}<0.05)$. The high incidence of mortality in spring was mainly due to the five-fold increase in mortality on the natural reef compared with previous sampling periods (Table 1), likely as a result of increased sedimentation associated with nearby coastal development (see below). There were no differences in mortality in the earlier sampling periods on the natural reef when spring natural reef mortality was excluded to account for potential anthropogenic effects (Friedman's ANOVA: $X=0, P>0.05$ ). Coral mortality did not differ among the leeward and windward breakwaters and the natural reef during any sampling period (Table 1; $H_{(\mathrm{n}=43)}$ : Summer $=6.7$, Fall $=7.5$, Winter $=0.6$, Spring $=4.2, \mathrm{P}>0.05$ each).

Although there were no differences in the overall density of coral colonies lost to mortality among reef types (see above), mortality affected a higher proportion of the population on leeward breakwaters as a result of a smaller overall population sizes. Nearly a third of all corals on the leeward breakwater were lost during the year, compared with less than a tenth on the windward breakwater (Fig. 4). The natural reef lost approximately a fifth of coral colonies over the year, but two-thirds of this mor- 


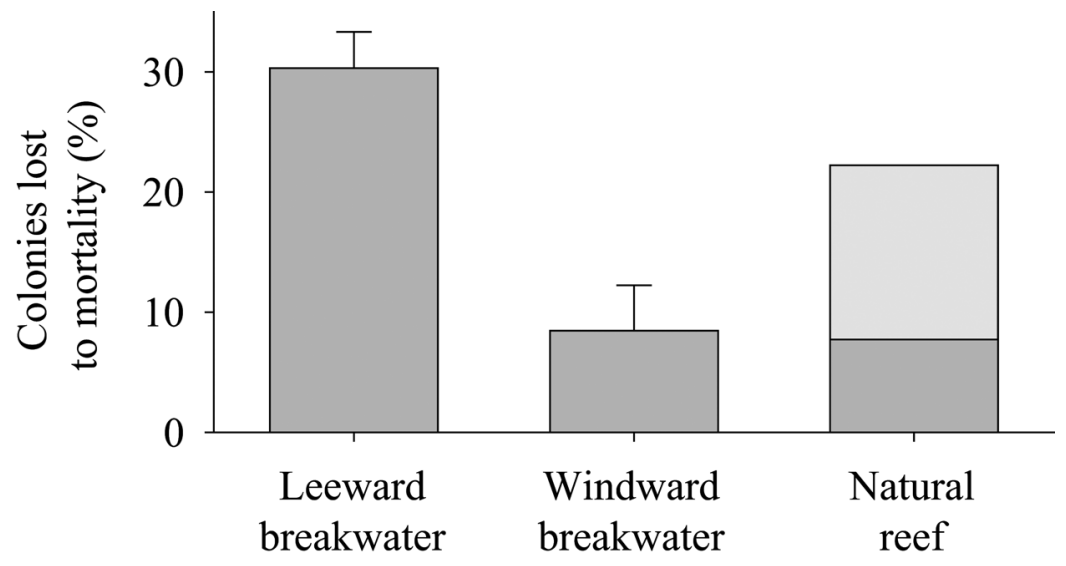

Figure 4. Mean $( \pm$ SE) percentage of colonies lost to mortality out of the whole coral community at each location over one year. Light shading on natural reef indicates percent lost in spring alone.

tality was during the spring (Fig. 4, light shading), which likely resulted from nearby marine construction activity.

Mortality was entirely restricted to juvenile corals on both the leeward and windward breakwaters, and all but one colony on the natural reef. A frequency distribution of mortality versus colony size indicated that coral mortality was highest in new recruits $\left(<1.5 \mathrm{~cm}^{2}\right.$; Fig. 5). On the leeward breakwater, coral mortality was almost entirely restricted to colonies $<3 \mathrm{~cm}^{2}$, while mortality mainly affected larger-sized colonies on the windward breakwater and the natural reef (Fig. 5).

Two species were responsible for all demographic change on breakwaters. Despite representing only $0.3 \%$ of cover, Siderastrea savignyana (Milne-Edwards and Haime, 1850) made up $90 \%$ of all recruits on breakwaters and were the only recruits observed on the windward sites. This dominance in recruitment was balanced by high mortality, with this species comprising $70 \%$ of all mortality on breakwaters. Favia pallida made up the remainder of breakwater recruitment and mortality, with $10 \%$ of recruitment and 30\% of mortality occurring in this species. On the natural reef, demographic change was more evenly divided among three species: $P$. harrisoni, $P$.
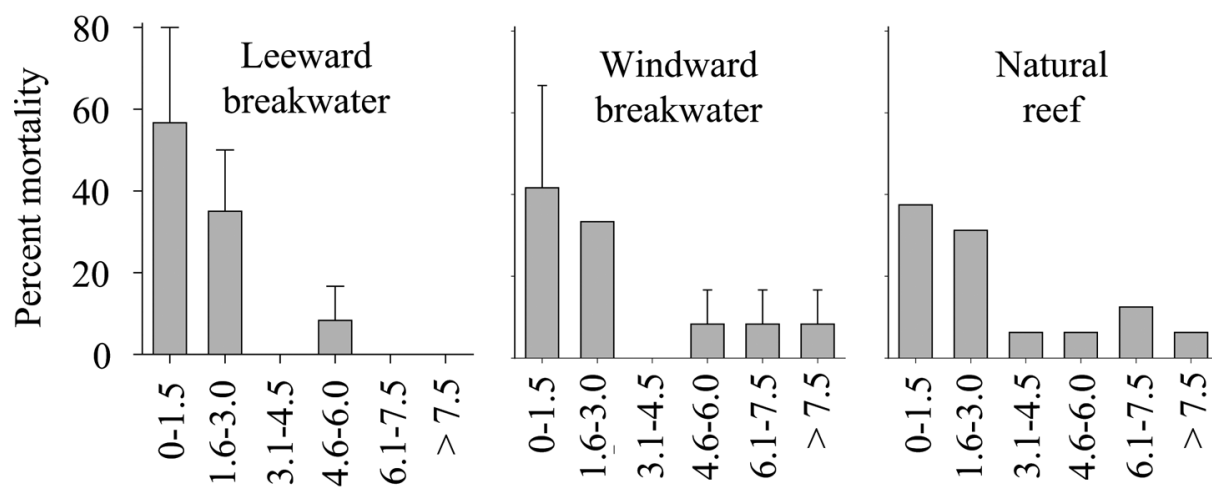

Size class $\left(\mathrm{cm}^{2}\right)$

Figure 5. Relationship between colony size and percent mortality (mean \pm SE) on leeward and windward breakwaters and the natural reef. 


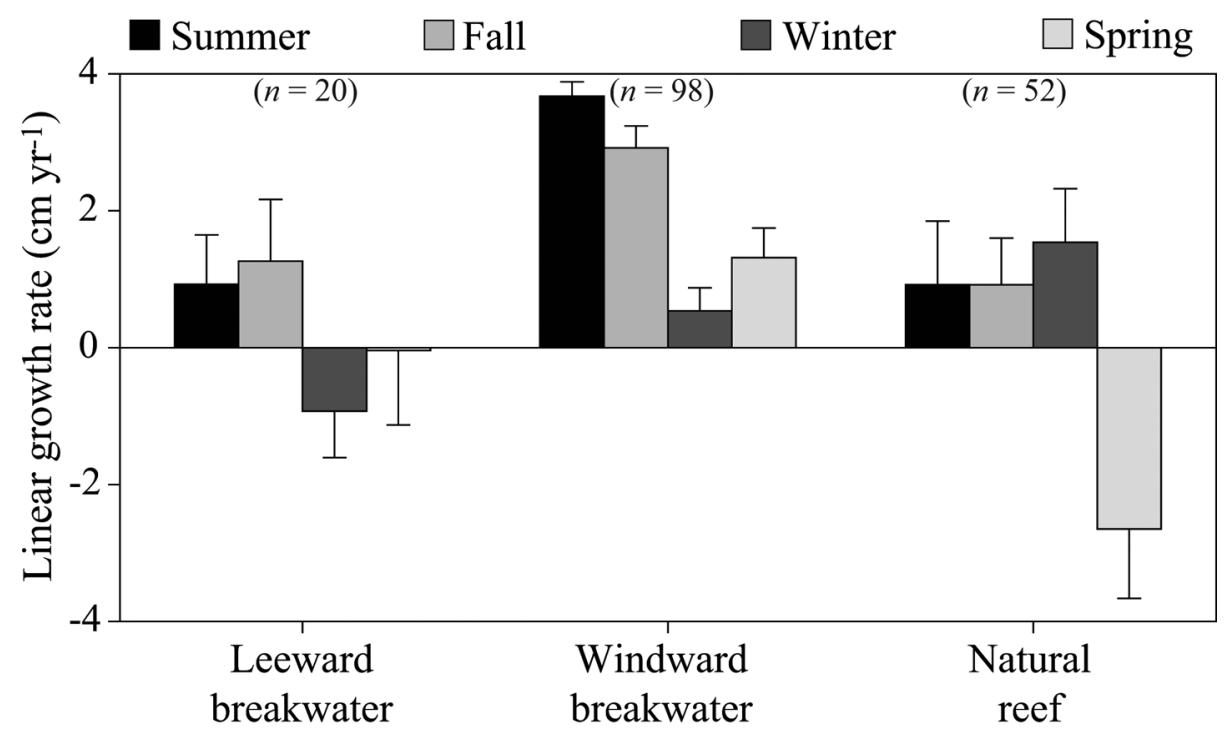

Figure 6. Mean $( \pm \mathrm{SE})$ seasonal coral growth rates for each reef type $\left(\mathrm{cm} \mathrm{yr}^{-1}\right)$. Sample size indicated in parentheses.

lutea, and Coscinaraea monile (Forsskål, 1775) (27.3\% of recruitment each). This recruitment was nearly balanced by mortality in P. lutea and C. monile (31.3\% of mortality each), although mortality was lower in P. harrisoni (18.8\% of mortality).

Coral Growth.-Annual linear coral growth rate, averaged across all sites and seasons, was $1.31 \pm 0.6 \mathrm{~cm} \mathrm{yr}^{-1}$. However, there were fluctuations in coral growth rates among sampling periods and reef types, with coral growth rates becoming negative as a result of partial colony mortality resulting in colony shrinkage during the winter on leeward breakwaters and during the spring on natural reefs (Fig. 6). Repeated measures ANOVA showed a significant interaction in growth rates between sampling periods and location $\left(F_{(6,501)}=3.6, \mathrm{P}<0.01\right)$.

Post-hoc Tukey's unequal-N HSD tests were used to explore differences in growth rates among reef types and sampling periods. There was no significant difference in coral growth rates between the leeward and windward sites and between leeward sites and the natural reef sites during any season $(\mathrm{P}>0.05$ each), likely due to variation associated with the low number of colonies on the leeward breakwaters. However, growth rates on windward breakwaters were significantly higher than those on the natural reef during both summer and spring (Fig. 6; $\mathrm{P}<0.05$ and $\mathrm{P}<0.01$, respectively).

Leeward breakwaters had negative coral growth rates during the winter and spring (due to partial colony mortality: Fig. 6), although there was no significant difference in overall growth rates among sampling periods (Tukey's unequal-N HSD test: P > 0.05 each). Windward breakwater coral growth rates also declined in the winter (Fig. 6), with significantly lower growth rates in the winter and spring than in summer (Tukey's unequal-N HSD test: $\mathrm{P}<0.001$ each). On the natural reef there were no significant differences in coral growth rates among sampling periods, except in spring, with coral growth rates declining significantly in this period compared with preced- 




Particle size

Figure 7. Sediment particle-size distribution of (A) in situ benthic sediments and (B) water column sediments among reef types. Water column sediments on the natural reef are shown both before and after breakwater nearby construction.

ing seasons $(\mathrm{P}<0.05$ each $)$ and partial colony mortality in $61.5 \%$ of colonies. This followed construction of a breakwater near this natural reef site.

Colony Size and Growth Rates.-Linear regression showed that there was a significant positive relationship between colony diameter and mean annual growth rate $\left(\mathrm{cm} \mathrm{yr}^{-1}\right)$ on the windward breakwater $\left(F_{(1,91)}=63.9, \mathrm{P}<0.001 ; \mathrm{r}=0.64\right)$, but not on the leeward breakwater $\left(F_{(1,17)}=1.2 ; \mathrm{r}=0.25\right)$ nor the natural reef $\left(F_{(1,45)}=0.85 ; \mathrm{r}=\right.$ $0.13)$. However, there was a significant positive relationship between colony size and mean annual growth rates on natural reefs when spring values were excluded $\left(F_{(1,45)}\right.$ $=6.6, \mathrm{P}<0.05 ; \mathrm{r}=0.4)$.

Particle Size Distribution.-Particle size distributions for both the in situ benthic sediments (Fig. 7A) and water column sediments (Fig. 7B) differed substantially between windward and leeward reefs. On leeward breakwaters both in situ benthic sediments (Fig. 7A) and the water column sediment collectors (Fig. 7B) were dominated by sediments in the smallest size class $(>63 \mu \mathrm{m})$. In contrast, the windward breakwater sediments were proportionally dominated by particles between 125 and $250 \mu \mathrm{m}$ in diameter (in situ: $47 \%$ of sediments; sediment collectors: $34 \%$ of sediments). Benthic sediments on the natural reef were dominated by particles 
in the largest size-classes (Fig. 7A), with over three-quarters of sediments $>250 \mu \mathrm{m}$ in diameter. The size-distribution of water column sediments on the natural reef closely resembled the distribution of water column sediments at windward breakwaters in winter 2008 (prior to construction of a breakwater near the natural reef in April 2008). However, following breakwater construction near the natural reef, water column sediments become dominated by the $<63 \mu \mathrm{m}$ particle size-class (Fig. $7 \mathrm{~B}$ ).

\section{Discussion}

Coastal defense structures such as breakwaters, jetties, and sea walls are increasingly common features in coastal urban areas. These structures can develop diverse and abundant benthic and fish assemblages (Lincoln-Smith et al., 1994; Pondella et al., 2002; Bulleri, 2005b; Guidetti et al., 2005; Moschella et al., 2005; Burt et al., 2009a,b), which may provide benefits to local ecosystem productivity and related economic activity using these resources. The results of this study indicate that orientation to wave exposure is an important factor structuring the development of corals on breakwaters, with implications for both community structure and function. The results also indicate that the influence of wave exposure can lead to patterns and processes in corals on breakwaters that are more, or are less, similar to those on natural reefs. However, while this natural reef is representative of coral communities in Dubai and is the last large patch reef in the area, thus serving as a useful comparison for this environment, it is a single site that may not be representative of the true variability of natural systems suggesting caution in generalizing these patterns to natural reefs elsewhere.

The leeward breakwater appears to offer a sub-optimal habitat for coral community development compared with the windward breakwaters and natural reef. Coral cover on the leeward breakwater was significantly lower than on the natural reef, and low compared with that of the windward breakwater. The low cover on leeward breakwaters is likely due to its young age ( $5.5 \mathrm{yrs}$ ) compared with the natural reef, as well as high early post-settlement mortality vs the other reef types. Examination of colony sizes indicated high mortality during early life on the leeward breakwater where only a quarter of corals survived beyond the juvenile stage, compared with over half of colonies on the windward breakwater and the natural reef. This is reflected in the relationship between colony size and mortality, where coral mortality on the leeward breakwater was almost entirely restricted to recent recruits $<3 \mathrm{~cm}^{2}$. In addition, the loss of corals had a disproportional effect on the leeward breakwater community due to low overall coral abundance, resulting in the annual loss of nearly a third of all colonies. Coral recruitment rates and growth rates were comparable among all reef types, and growth rates were unrelated to colony size on the leeward breakwater, indicating that these processes likely had little influence on the low coral cover on the leeward breakwater.

The results of this study suggest that differences in the cover and composition among the three reef types may be associated with differences in the relative abundance of fine sediments. The leeward sites have a significant wave height that is half of that on the exposed windward face (Smit et al., 2005), which could lead to differences in the degree and intensity of water movement and flushing between sites. This lower water movement at the leeward sites can explain the dominance of fine sediment particles within the water column and in the benthos compared with wind- 
ward sites. An increase in the deposition of fine sediments associated with reduced wave energy is also reflected in the shift in particle size distribution on the natural reef following breakwater construction in 2008. Following this construction, the reef was in the lee of the new breakwater, which reduced water flow and increased the possibility of deposition of fine sediments within this area; particle size distribution within the area abruptly shifted after construction from one with relatively limited fine sediments to one in which over four-fifths of the sediments in the water column were ultra-fine particles.

It is likely that the difference in sedimentation between sites had a substantial effect on the composition and structure of the resident benthic community. On the leeward breakwaters more than three-quarters of the substratum is dominated by turf algae and bivalves, and little bare space is available for colonization (J. Burt unpubl. data). In contrast, bare pavement makes up almost half of the substrata on the windward breakwater (J. Burt unpubl. data). The high turf abundance on leeward sites likely results from the low densities of sea urchins here (J. Burt pers. obs.), with urchin recruitment and survivorship possibly impaired by the high abundance of fine sediments associated with the leeward breakwaters (Purcell, 2000; Walker, 2007). As both fine sedimentation and algae can inhibit coral recruitment, growth, and survival (Hodgson, 1990; McCook et al., 2001; Birrell et al., 2005; Crabbe and Smith, 2005; Box and Mumby, 2007; Birrell et al., 2008), it is likely that the physical and biological conditions resulting from low wave action and concurrent water movement contributed to the low coral cover, skewed size distribution, and proportionately high mortality of corals on the leeward breakwater. Further investigation of these factors is warranted.

Despite the evident differences in coral demography between windward and leeward breakwaters, our results indicate that the processes structuring coral community development on the windward breakwater sites appear comparable to that of the natural reef during this year, although adjacent development makes generalization of comparisons difficult. After only 5.5 yrs since construction, the windward breakwater has developed 9.8\% coral cover compared with $24.1 \%$ on the natural reef site, and coral recruitment, mortality, and growth rates were comparable between these reef types. However, this one year (July 2007 to July 2008) may not be representative of longer term changes in these communities. On the windward breakwater there may be an increase in recruitment as these colonies reach sexual maturity, with fecundity increasing as colonies grow larger (Soong and Lang, 1992; Sakai, 1998; Kai and Sakai, 2008). However, this will depend on whether or not there is sufficient larval retention in the area to support local enhancement. In addition, it is also likely that community structure and dynamics will change on the natural reef. The natural reefs are exposed to recurrent mass mortality every 10-15 yrs (Riegl, 2002a,b; Riegl and Purkis, 2009), and are currently in the process of recovery (Burt et al., 2008). Such events particularly affect the acroporids dominating these natural reefs while having minimal impacts on the faviids and poritids which dominate breakwaters (Riegl, 2002a,b; Sheppard and Loughland, 2002). This suggests that bleaching events predicted to occur with increasing frequency and magnitude in this region (Coles and Brown, 2003; Sheppard, 2003) are likely to differentially impact coral community structure and dynamics on the natural reefs. In addition, coastal development is likely to further exacerbate differences in coral cover and composition between natural reefs and windward breakwaters. The development of breakwaters adjacent to the natural reef 
was associated with a more than four-fold increase in whole colony mortality, a near doubling of partial colony mortality, and a decline in coral growth rates such that colonies were shrinking by $25 \mathrm{~cm}^{2} \mathrm{yr}^{-1}$ following construction. All of these changes in the coral communities were likely a result of changes in local water quality, with increased deposition of ultra-fine sediments following breakwater construction. It is likely that on-going and planned coastal developments adjacent to these natural reefs will continue to have negative impacts on these coral communities in the coming years. Overall, this suggests that while coral community dynamics on the windward breakwater and the natural reef are currently comparable, natural and anthropogenic changes are likely to result in their divergence in the long term. These results also highlight the importance of "shifting baselines" in ecological studies of developed coastlines. Both earlier thermal bleaching events and the construction impacts observed in this and earlier studies have modified the community structure on natural reefs in this area, complicating comparisons with breakwater communities which are also undergoing community succession. While such processes necessitate caution in broad-stroke generalization of these results to other areas, they do reflect the reality of the substantial modification of coastal systems worldwide with increasing coastal development (Rogers, 1990; Hilton and Manning, 1995; Wolanski et al., 2009; Sheppard et al., 2010).

Overall coral recruitment densities of $1.9 \pm 0.7$ recruits $\mathrm{m}^{-2} \mathrm{yr}^{-1}$ were observed across sites in this study, which is comparable to recruit densities observed on natural substrates in the Caribbean (Chiappone and Sullivan, 1996), the Red Sea (Abelson et al., 2005), and the Great Barrier Reef (Connell et al., 1997). In terms of growth rates, corals associated with the breakwater and natural reefs grew at an average rate of $13.0 \pm 6.0 \mathrm{~mm} \mathrm{yr}^{-1}$, substantially faster than average overall growth rates of corals in the Caribbean (3.4 $\pm 0.2 \mathrm{~mm} \mathrm{yr}^{-1}$; Edmunds, 2007), the Red Sea (4.9 $\mathrm{mm} \mathrm{yr}^{-1}$; Glassom and Chadwick, 2006), and subtropical Australian reefs (0.6 to $2.0 \mathrm{~mm} \mathrm{yr}^{-1}$; Wilson and Harrison, 2005). These are important observations, as corals in Dubai are regularly exposed to temperature ranges exceeding $20^{\circ} \mathrm{C}$, summer sea maxima $>35^{\circ} \mathrm{C}$, and salinities exceeding 45 (Reynolds, 1993; Sheppard et al., 2010). Overall, this suggests that despite the severity of environmental conditions in the Persian Gulf, coral recruitment and growth rates are comparable to or higher than other areas, demonstrating the resilience of corals to stress in this area, and the potential for adaptation to environmental extremes. Interestingly, coral growth rates were positively correlated with colony size in this study, while studies elsewhere generally show reduced growth rates in larger colonies (Chadwick-Furman et al., 2000; Goffredo et al., 2004; Bramanti et al., 2005; Carpenter and Edmunds, 2006). This likely reflects the relatively small size of colonies in this study versus in other areas. There were very few colonies $>125 \mathrm{~cm}^{2}$ (12.6 cm diameter) on either the breakwaters or natural reef examined in this study as a result of the young breakwater age or the ongoing recovery from bleaching, respectively. As a result, many of the colonies examined here have not yet reached sexual maturity. Given that coral growth rates generally decline as colonies become reproductive (Richmond, 1987; Ward, 1995; Guzman and Tudhope, 1998; Mendes, 2004), it is likely that the current positive relationship between size and growth will change in the coming years as these colonies become reproductive.

The natural reefs within the gulf are increasingly being degraded by an array of both natural and anthropogenic disturbances (Riegl, 2002a; Sheppard et al., 2010), 
and thus represent a shifting baseline that is in a state of constant change due to external impacts and subsequent recovery (Riegl, 2002b; Burt et al., 2008; Riegl and Purkis, 2009). The results of our study indicate that windward breakwaters can develop coral communities that are comparable in some respects to the degraded natural reef systems in this area, and this and earlier work indicate that windward breakwaters in Dubai have potential to form an important reef-like coral community in the future (Burt et al., 2009a,b). However, given the unique biological and environmental conditions of the gulf and the use of only one reef site for comparison here, caution in generalizing the results to natural reefs elsewhere is warranted.

Overall, the results of this study highlight the importance of breakwaters as an artificial reef habitat on which coral communities can develop. With appropriate design for wave exposure, such structures can contain coral communities with comparable coral cover, demographics, and growth rates to natural reefs. However, the placement of such coastal developments can be of far more importance than design features. The construction of coastal developments on or near reefs has resulted in the direct loss or degradation of reefs worldwide (Rogers, 1990; Hilton and Manning, 1995; Wolanski et al., 2009), including those in the Persian Gulf (Price et al., 1993; Sheppard et al., 2010). Dubai, in particular, has been substantially impacted by development, with the loss of over $8 \mathrm{~km}^{2}$ of coral habitat with the construction of the Palm Jebel Ali (Burt et al., 2008), destruction of several more dense and diverse coral patches with the construction of the Dubai Waterfront (Burt et al., 2009b), and the further degradation of reefs witnessed in this study, where partial- and whole-colony mortality increased and average colonies shrank on the natural reef in association with nearby breakwater construction. Although it could be suggested that breakwater construction may mitigate these impacts by creating novel hard-bottom habitats upon which coral communities will develop, results of this and other studies (Burt et al., 2009b) indicate that the composition of these breakwater coral communities is distinct throughout their successional development, and that breakwater coral communities are not surrogates for natural reefs. Appropriate protection of natural coral reef habitats should be a priority for marine management, with the benefits of design features of breakwaters only considered for areas in which development will have minimal impacts.

\section{ACKNOWLEDGMENTS}

Our thanks go to M. Bernardo and N. Zehwali for assistance in the lab and field and K. Jenahi for assistance with image analysis. This project was supported by funds from Zayed University and Nakheel PJSC and their support is appreciated. This study was part of the Nakheel - UNU-INWEH research program undertaken to understand the ecological dynamics of ecosystems in the vicinity of Nakheel marine projects.

\section{Literature Cited}

Abelson, A., R. Olinky, and S. Gaines. 2005. Coral recruitment to the reefs of Eilat, Red Sea: temporal and spatial variation, and possible effects of anthropogenic disturbances. Mar. Pollut. Bull. 50: 576-582.

Airoldi, L., M. Abbiati, M. W. Beck, S. J. Hawkins, P. R. Jonsson, D. Martin, P. S. Moschella, A. Sundelof, R. C. Thompson, and P. Aberg. 2005. An ecological perspective on the deploy- 
ment and design of low-crested and other hard coastal defence structures. Coast. Eng. 52: 1073-1087.

Bacchiocchi, F. and L. Airoldi. 2003. Distribution and dynamics of epibiota on hard structures for coastal protection. Estuar. Coast. Shelf Sci. 56: 1157-1166.

Baine, M. 2001. Artificial reefs: a review of their design, application, management and performance. Ocean Coast. Manage. 44: 241-259.

Bak, R. and M. Engel. 1979. Distribution, abundance and survival of juvenile hermatypic corals (Scleractinia) and the importance of life-history strategies in the parent coral community. Mar. Biol. 54: 341-352.

Birrell, C., L. McCook, and B. Willis. 2005. Effects of algal turfs and sediment on coral settlement. Mar. Pollut. Bull. 51: 408-414.

Birrell, C. L., L. J. McCook, B. L. Willis, and G. A. Diaz-Pulido. 2008. Effects of benthic algae on the replenishment of corals and the implications for the resilience of coral reefs. Ocean. Mar. Biol. Annu. Rev. 46: 25-63.

Box, S. J. and P. J. Mumby. 2007. Effect of macroalgal competition on growth and survival of juvenile Caribbean corals. Mar. Ecol. Prog. Ser. 342: 139-149.

Bramanti, L., G. Magagnini, L. De Maio, and G. Santangelo. 2005. Recruitment, early survival and growth of the Mediterranean red coral Corallium rubrum (L 1758), a 4-year study. J. Exp. Mar. Biol. Ecol. 314: 69-78.

Bulleri, F. 2005a. Experimental evaluation of early patterns of colonisation of space on rocky shores and seawalls. Mar. Environ. Res. 60: 355-374.

. 2005b. Role of recruitment in causing differences between intertidal assemblages on seawalls and rocky shores. Mar. Ecol. Prog. Ser. 287: 53-65.

and L. Airoldi. 2005. Artificial marine structures facilitate the spread of a nonindigenous green alga, Codium fragile ssp. tomentosoides, in the north Adriatic Sea. J. Appl. Ecol. 42: 1063-1072.

, M. Abbiati, and L. Airoldi. 2006. The colonisation of human-made structures by the invasive alga Codium fragile ssp. tomentosoides in the north Adriatic Sea (NE Mediterranean). Hydrobiologia 555: 263-269.

Burt, J., A. Bartholomew, and P. Usseglio. 2008. Recovery of corals a decade after bleaching in Dubai, United Arab Emirates. Mar. Biol. 154: 27-36.

A. Bauman, A. Saif, and P. F. Sale. 2009a. Coral recruitment and early benthic community development on several materials used in the construction of artificial reefs and breakwaters. J. Exp. Mar. Biol. Ecol. 373: 72-78.

, P. Usseglio, A. Bauman, and P. F. Sale. 2009b. Are artificial reefs surrogates of natural habitats for corals and fish in Dubai, United Arab Emirates? Coral Reefs 28: 663-675.

Carpenter, R. C. and P. J. Edmunds. 2006. Local and regional scale recovery of Diadema promotes recruitment of scleractinian corals. Ecol. Lett. 9: 268-277.

Carr, M. and M. Hixon. 1997. Artificial reefs: the importance of comparisons with natural reefs. Fisheries 22: 28-33.

Chadwick-Furman, N. E., S. Goffredo, and Y. Loya. 2000. Growth and population dynamic model of the reef coral Fungia granulosa Klunzinger, 1879 at Eilat, northern Red Sea. J. Exp. Mar. Biol. Ecol. 249: 199-218.

Chiappone, M. and K. M. Sullivan. 1996. Distribution, abundance and species composition of juvenile scleractinian corals in the Florida Reef Tract. Bull. Mar. Sci. 58: 555-569.

Clark, S. and A. J. Edwards. 1999. An evaluation of artificial reef structures as tools for marine habitat rehabilitation in the Maldives. Aqua. Conserv. Mar. Freshw. Ecosys. 9: 5-21.

Clynick, B. G., M. G. Chapman, and A. J. Underwood. 2008. Fish assemblages associated with urban structures and natural reefs in Sydney, Australia. Austral. Ecol. 33: 140-150.

Coles, S. and B. Brown. 2003. Coral bleaching-capacity for acclimatization and adaptation. Adv. Mar. Biol. 46: 183-223. 
Connell, J., T. Hughes, and C. Wallace. 1997. A 30-year study of coral abundance, recruitment, and disturbance at several scales in space and time. Ecol. Monogr. 67: 461-488.

Crabbe, M. J. C. and D. J. Smith. 2005. Sediment impacts on growth rates of Acropora and Porites corals from fringing reefs of Sulawesi, Indonesia. Coral Reefs 24: 437-441.

Edmunds, P. J. 2007. Evidence for a decadal-scale decline in the growth rates of juvenile scleractinian corals. Mar. Ecol. Prog. Ser. 341: 1-13.

Glassom, D. and N. E. Chadwick. 2006. Recruitment, growth and mortality of juvenile corals at Eilat, northern Red Sea. Mar. Ecol. Prog. Ser. 318: 111-122.

Goffredo, S., G. Mattioli, and F. Zaccanti. 2004. Growth and population dynamics model of the Mediterranean solitary coral Balanophyllia europaea (Scleractinia, Dendrophylliidae). Coral Reefs 23: 433-443.

Guidetti, P., S. Bussotti, and F. Boero. 2005. Evaluating the effects of protection on fish predators and sea urchins in shallow artificial rocky habitats: a case study in the northern Adriatic Sea. Mar. Environ. Res. 59: 333-348.

Guzman, H. M. and A. W. Tudhope. 1998. Seasonal variation in skeletal extension rate and stable isotopic (C-13/C-12 and O-18/O-16) composition in response to several environmental variables in the Caribbean reef coral Siderastrea siderea. Mar. Ecol. Prog. Ser. 166: 109-118.

Hansen, B. 2005. Artificial islands reshape Dubai coast. Civil Engineering 75: 12-13.

Hilton, M. J. and S. S. Manning. 1995. Conversion of coastal habitats in Singapore: Indications of unsustainable development. Environ. Conserv. 22: 307-322.

Hodgson, G. 1990. Sediment and the settlement of larvae of the reef coral Pocillopora damicornis. Coral Reefs 9: 41-43.

Kai, S. and K. Sakai. 2008. Effect of colony size and age on resource allocation between growth and reproduction in the corals Goniastrea aspera and Favites chinensis. Mar. Ecol. Prog. Ser. 354: 133-139.

Kohler, K. and S. Gill. 2006. Coral Point Count with Excel extensions (CPCe): a Visual Basic program for the determination of coral and substrate coverage using random point count methodology. Comp. Geosci. 32: 1259-1269.

Lincoln-Smith, M., C. Hair, and J. Bell. 1994. Man-made rock breakwaters as fish habitats: comparisons between breakwaters and natural reefs within an embayment in southeastern Australia. Bull. Mar. Sci. 55: 1344.

McCook, L., J. Jompa, and G. Diaz-Pulido. 2001. Competition between corals and algae on coral reefs: a review of evidence and mechanisms. Coral Reefs 19: 400-417.

Mendes, J. 2004. Timing of skeletal band formation in Montastraea annularis: relationship to environmental and endogenous factors. Bull. Mar. Sci. 75: 423-437.

Miller, M. 2002. Using ecological processes to advance artificial reef goals. ICES J. Mar. Sci. 59: S27-S31.

Moschella, P. S., M. Abbiati, P. Aberg, L. Airoldi, J. M. Anderson, F. Bacchiocchi, F. Bulleri, G. E. Dinesen, M. Frost, E. Gacia, et al. 2005. Low-crested coastal defence structures as artificial habitats for marine life: using ecological criteria in design. Coast. Engin. 52: 1053-1071.

Pondella, D., J. Stephens, and M. Craig. 2002. Fish production of a temperate artificial reef based on the density of embiotocids. ICES J. Mar. Sci. 59: S88-S93.

Price, A. R. G., C. R. C. Sheppard, and C. M. Roberts. 1993. The Gulf-its biological setting. Mar. Pollut. Bull. 27: 9-15.

Purcell, S. W. 2000. Association of epilithic algae with sediment distribution on a windward reef in the northern Great Barrier Reef, Australia. Bull. Mar. Sci. 66: 199-214.

Reinicke, G. B., D. K. Kroll, and H. Schuhmacher. 2003. Patterns and changes of reef-coral communities at the Sanganeb-Atoll (Sudan, central Red Sea): 1980 to 1991. Facies 49: 271-298.

Reynolds, M. 1993. Physical oceanography of the Gulf, Strait of Hormuz, and the Gulf of Oman: results from the Mt Mitchell expedition. Mar. Pollut. Bull. 27: 35-39. 
Richmond, R. H. 1987. Energetic relationships and biogeographical differences among fecundity, growth and reproduction in the reef coral Pocillopora damicornis. Bull. Mar. Sci. 41: 594-604.

Riegl, B. 1999. Corals in a non-reef setting in the southern Arabian Gulf (Dubai, UAE): fauna and community structure in response to recurring mass mortality. Coral Reefs 18: 63-73. 2002a. Effects of the 1996 and 1998 positive sea-surface temperature anomalies on corals, coral diseases and fish in the Arabian Gulf (Dubai, UAE). Mar. Biol. 140: 29-40. 2002b. Phoenix from the ashes? Repetitive mass mortality and the biogeology of southern Arabian Gulf (United Arab Emirates) coral systems. The Vienna School of Marine Biology: 137-159.

and W. E. Piller. 1997. Distribution and environmental control of coral assemblages in northern Safaga Bay (Red Sea, Egypt). Facies 36: 141-162.

and S. Purkis. 2009. Model of coral population response to accelerated bleaching and mass mortality in a changing climate. Ecol. Model. 220: 192-208.

Rogers, C. S. 1990. Responses of coral reefs and reef organisms to sedimentation. Mar. Ecol. Prog. Ser. 62: 185-202.

, H. C. I. Fitz, M. Gilnack, and J. Hardin. 1984. Scleractinian coral recruitment patterns at Salt River Submarine Canyon, St. Croix, U.S. Virgin Islands. Coral Reefs 3: 69-76.

Sakai, K. 1998. Effect of colony size, polyp size, and budding mode on egg production in a colonial coral. Biol. Bull. 195: 319-325.

Sheppard, C. 2003. Predicted recurrences of mass coral mortality in the Indian Ocean. Nature 425: 294-297.

and R. Loughland. 2002. Coral mortality and recovery in response to increasing temperature in the southern Arabian Gulf. Aquat. Ecosyst. Health Manag. 5: 395-402.

, M. Al-Husiani, F. Al-Jamali, F. Al-Yamani, R. Baldwin, J. Bishop, F. Benzoni, E. Dutrieux, N. Dulvy, S. Durvasula, et al. 2010. The Gulf: a young sea in decline. Mar. Pollut. Bull. 60: 13-38.

Smit, F., G. Mocke, and K. Al-Zahed. 2005. Quantifying and managing the coastal response to major offshore developments in Dubai. Proc. 14th Biennial Coastal Zone Conference, NOAA Coastal Services Center, New Orleans, Louisiana. Available from: http://www.csc. noaa.gov/cz/CZ05_Proceedings/pdf\%20files/Smit.pdf via the Internet. Accessed 31 March 2010.

Soong, K. Y. and J. C. Lang. 1992. Reproductive integration in reef corals. Biol. Bull. 183: 418431.

Southward, A. J. and J. H. Orton. 1954. The effects of wave-action on the distribution and numbers of the commoner plants and animals living on the Plymouth Breakwater. J. Mar. Biol. Assoc. U.K. 33: 1-19.

Steiner, S. C. C. 2003. Stony corals and reefs of Dominica, Lesser Antilles. Atoll Res. Bull. 497508: A1-A15.

Vaselli, S., F. Bulleri, and L. Benedetti-Cecchi. 2008. Hard coastal-defence structures as habitats for native and exotic rocky-bottom species. Mar. Environ. Res. 66: 395-403.

Walker, J. W. 2007. Effects of fine sediments on settlement and survival of the sea urchin Evechinus chloroticus in northeastern New Zealand. Mar. Ecol. Prog. Ser. 331: 109-118.

Ward, S. 1995. Two patterns of energy allocation for growth, reproduction and lipid storage in the scleractinian coral Pocillopora damicornis. Coral Reefs 14: 87-90.

Wen, K., C. Hsu, K. Chen, M. Liao, C. Chen, and C. Chen. 2007. Unexpected coral diversity on the breakwaters: potential refuges for depleting coral reefs. Coral Reefs 26: 127.

Wilson, J. and P. Harrison. 2005. Post-settlement mortality and growth of newly settled reef corals in a subtropical environment. Coral Reefs 24: 418-421. 
Wolanski, E., J. A. Martinez, and R. H. Richmond. 2009. Quantifying the impact of watershed urbanization on a coral reef: Maunalua Bay, Hawaii. Estuar. Coast. Shelf Sci. 84: 259-268.

Date Submitted: 24 February, 2010.

DATE ACCEPTED: 8 June, 2010.

Available Online: 30 June, 2010.

Addresses: (J.B.) Biological Sciences, University of Windsor, Windsor, ON, N9B 3P4, Canada. Current Address: Faculty of Science, New York University-Abu Dhabi, PO Box 129188 Abu Dhabi, United Arab Emirates. (D.F., P.U., A.B., P.F.S.) United Nations University International Network on Water, Environment and Health (UNU-INWEH), 175 Longwood Road South, Suite 204, Hamilton, Ontario, L8P-0A1, Canada. Corresponding Author: (J.B.) E-mail: <John.Burt@nyu.edu>. 


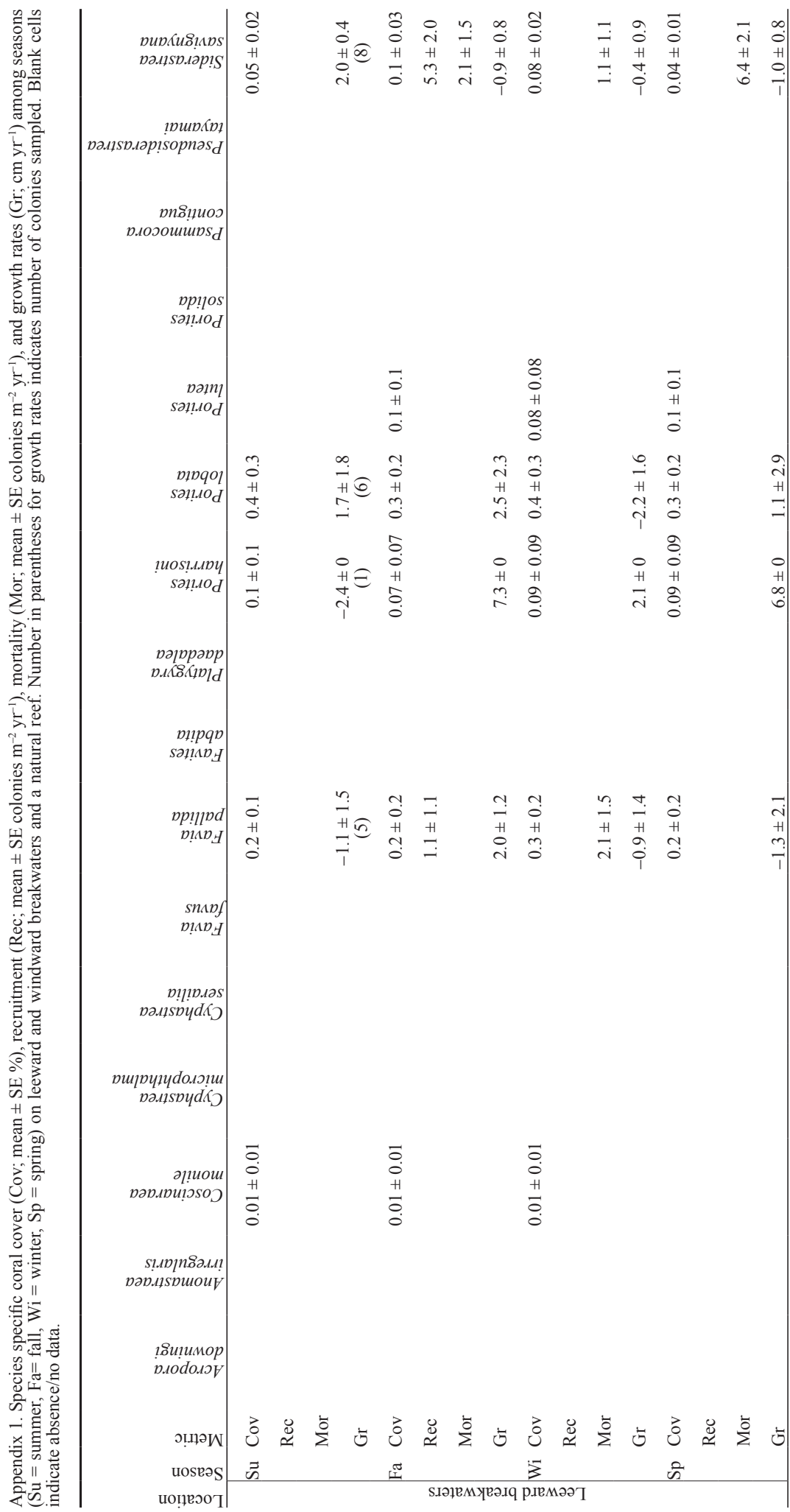




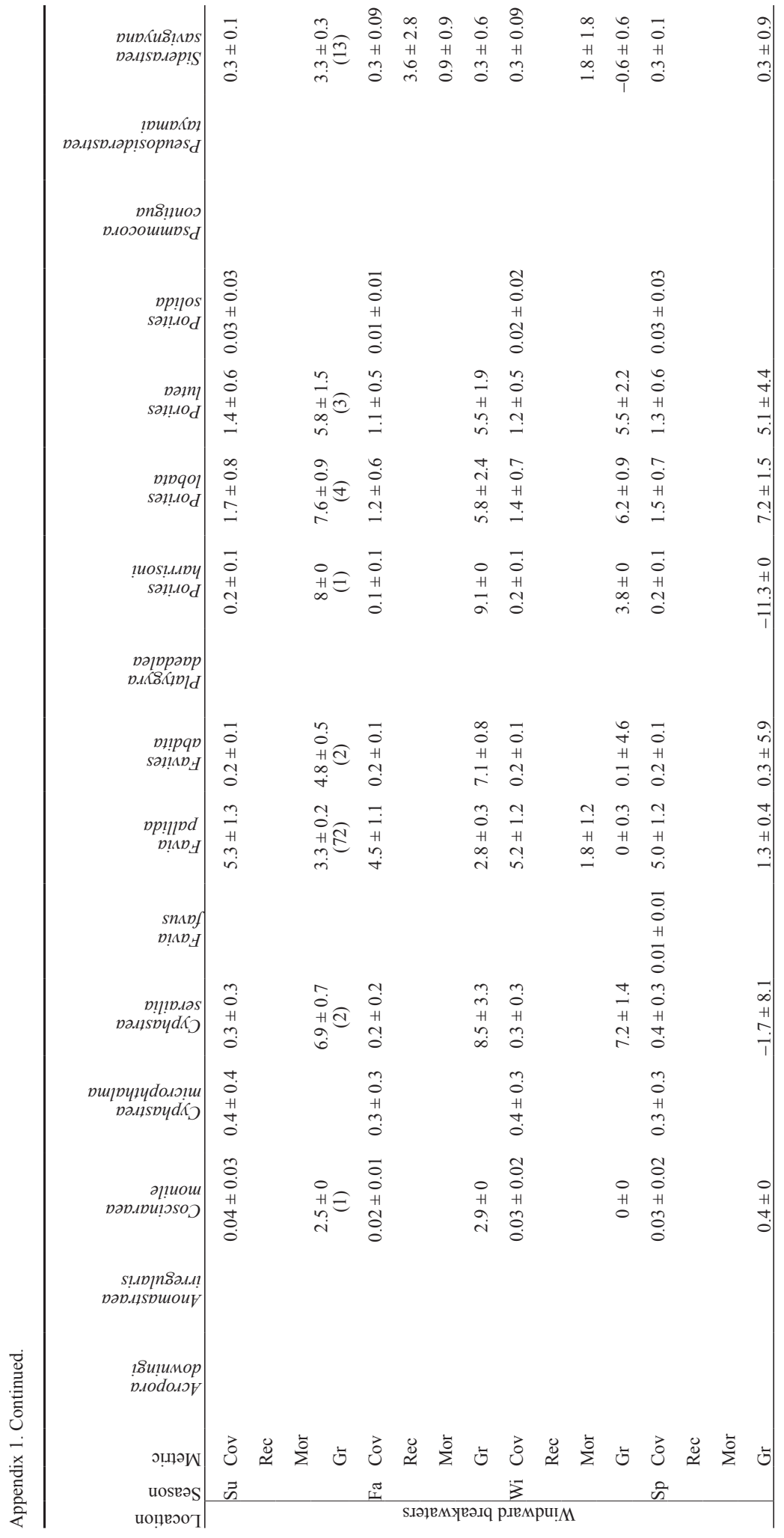




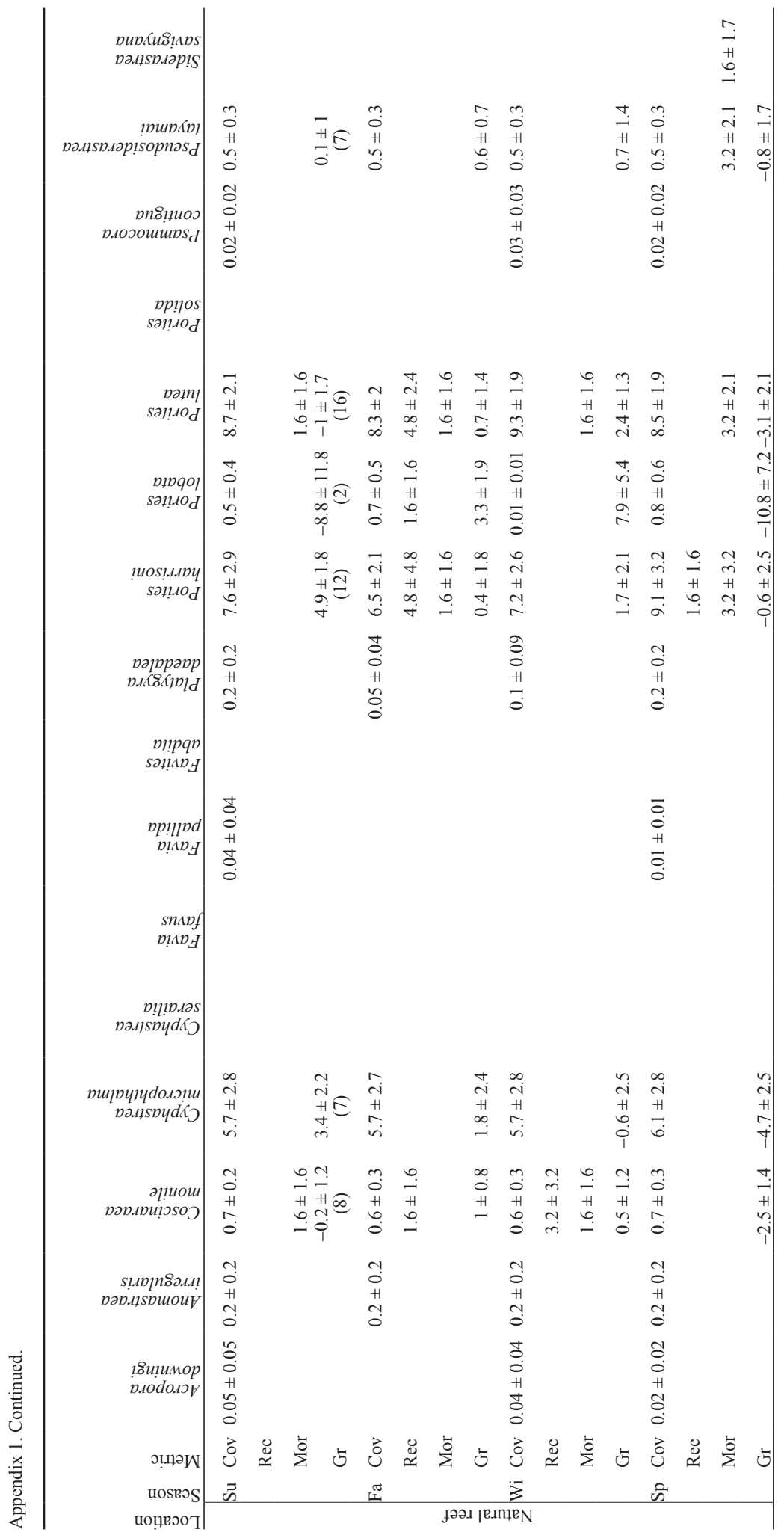

